\title{
Case Report: Evaluation strategies and cognitive intervention: the case of a monovular twin child affected by selective
}

\section{mutism [version 1; peer review: 3 approved]}

\author{
Micaela Capobianco1', Luca Cerniglia (DiD2 \\ 1 University of Rome "La Sapienza", Department of Psychology, via dei Marsi, Rome, 00185 , Italy \\ ${ }^{2}$ International Telematic University Uninettuno, Corso Vittorio Emanuele II, 39, Rome, 00186, Italy
}

V1 First published: 23 Feb 2018, 7:221

https://doi.org/10.12688/f1000research.14014.1

Latest published: 23 Feb 2018, 7:221

https://doi.org/10.12688/f1000research.14014.1

\section{Abstract}

The present work describes the assessment process, evaluation strategies, and cognitive intervention on a 9 years old child with selective mutism (SM), a monovular twin of a child also affected by mutism. Currently, the cognitive behavioral multimodal treatment seems the most effective therapeutic approach for children diagnosed with selective mutism (Capobianco \& Cerniglia, 2018). The illustrated case confirms the role of biological factors involved in mutacic disorder but also highlights the importance of environmental influences in the maintenance of the disorder with respect to relational and contextual dynamics (e.g. complicity between sisters, family relationships). The article discusses furthermore the importance of an early diagnosis as a predictor of positive treatment outcomes.

Keywords

Selective mutism; twins; assessment; intervention.

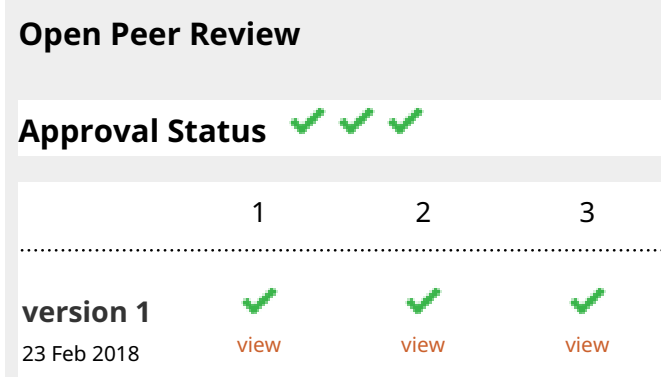

1. Mirco Fasolo, University of Chieti-Pescara, Chieti, Italy

2. Marco Bozzali, Brighton and Sussex Medical School, Brighton, UK

3. Deny Menghini, Children's Hospital Bambino Gesù, Rome, Italy

Any reports and responses or comments on the article can be found at the end of the article.

Corresponding author: Luca Cerniglia (I.cerniglia@uninettunouniversity.net)

Author roles: Capobianco M: Conceptualization, Writing - Original Draft Preparation, Writing - Review \& Editing; Cerniglia L: Supervision, Writing - Review \& Editing

Competing interests: No competing interests were disclosed.

Grant information: The author(s) declared that no grants were involved in supporting this work.

Copyright: $\odot 2018$ Capobianco M and Cerniglia L. This is an open access article distributed under the terms of the Creative Commons Attribution License, which permits unrestricted use, distribution, and reproduction in any medium, provided the original work is properly cited.

How to cite this article: Capobianco $\mathrm{M}$ and Cerniglia L. Case Report: Evaluation strategies and cognitive intervention: the case of a monovular twin child affected by selective mutism [version 1; peer review: 3 approved] F1000Research 2018, 7:221

https://doi.org/10.12688/f1000research.14014.1

First published: 23 Feb 2018, 7:221 https://doi.org/10.12688/f1000research.14014.1 


\section{Introduction}

Selective mutism (SM) is a developmental disorder of biological and environmental etiopathogenesis. It is characterized by the child's significant inability to speak in specific social situations (for instance at school) or in non-familiar circumstances. The clinical and research data confirm that SM is a complex etiological multifactorial disorder whose maintenance is connected with the interaction of biological (familiarity with shyness, preterm birth) (Capobianco \& Cerniglia, 2017) and environmental early factors (anxiety and overprotectiveness of the mother) (Capobianco et al., 2010; Capobianco et al., 2017; Capozzi et al., 2017; Pizzuto \& Capobianco, 2008) Analysis of the underlying thoughts and emotions in mutacic behavior reveals fear of judgment, fear of failure and being mocked, shame, depression, feelings of worthlessness or inadequacy,catastrophizing, and confirms the comorbidity between selective mutism and internalizing symptoms. The typical age of onset for selective mutism is between 3-6 years, even though the disorder gets usually diagnosed belatedly during the school age (around 7-8 years). It seems that the twins condition in presence of frequent associated additional biological and environmental conditions (prematurity, maternal stress, isolation) plays a crucial role in aggravating mutacic difficulties (Capobianco \& Cerniglia, 2017; Capobianco \& Cerniglia, 2018). The possibility to improve and change the symptomatology of SM-diagnosed children is strongly related to the severity of the disorder and the biological environmental factors implicated in each single case. Cognitive-behavioral intervention on the child has as its purpose to change the resulting cognitive biases and emotional states, but parallel efforts on the environmental dynamics that determine the disorder maintenance are needed (family and school).

\section{Case report}

$\mathrm{F}$ is a child with a belated diagnosis of selective mutism (diagnosed after the third grade of elementary school). The mutacic symptomatology appears particularly in the school environment, in interaction with teachers and peers during teaching activities. She has a monovular twin sister $(\mathrm{L})$ with the same diagnosis. She is born at 36 weeks without any particular pre- or perinatal problems. The mother describes F's development as regular through the "normal" stages and does not recall any developmental problems in the motor and/or linguistic realms during F's first years of life (Capobianco et al., 2017; Pizzuto \& Capobianco, 2008).

In short, $\mathrm{F}$ has always been a very shy girl, showing difficulties and fear in relating to non- familiar people. F has always perceived similar situations with an intense discomfort, anxiety and concern and has learned to react through inhibition, behavioral and verbal withdrawal. As a result of functional evaluation (cognitive and projective tests), spontaneous observation and exploration of the $\mathrm{ABC}$ (through various simulation techniques with characters, drawings, written questions and cartoons) emerges fear of judgment, fear of failure and being mocked, being made fun of, ("everyone will laugh at me"), shame, and the fact that others might notice this feeling. Depressiveness and catastrophizing prevail over the possible consequences on others of her speaking, her perception of inadequacy and her feelings of worthlessness ("I am afraid to make a mistake", "I didn't study", "I am not capable"). F shows her discomfort via "critical-provocative" behavior especially when her sister L is present, although the twins seem to have a strong complicity: "a mute complicity" in keeping the mutism part.

Maternal relationship. The mother's behavior represents an important maintenance factor of F's mutism. The girl shows indeed an anxious-dependent attachment style (Pattern $\mathrm{C}$ ) towards the mother. The mother actually appears to be anxious and worried showing a pressure attitude to make the girl speak (sometimes even punitive), and she often replaces $F$ in her responsibilities. Another important aspect is the confrontation with F's twin sister. The mother often tends to compare the two sisters. This creates conflict situations and a quest for attention by $\mathrm{F}$, who uses various maternal affection manipulation strategies.

Maternal thoughts and emotional states. During the interviews, the mother shows extreme attention to maintaining a positive image in front others and a propensity to avoid feelings of shame to which she gives a meaning of failure, devaluation and humiliation. These aspects are strongly connected to her life story and particularly to experiences of abandonment and maltreatment. Her necessity not to feel ashamed and her focus on avoiding situations, in which she could be exposed to that risk, have an extreme importance to the mother of $\mathrm{F}$ and $\mathrm{L}$.

The belated diagnosis has led $\mathrm{F}$ to reinforce her behavioral style such that, by now, has became habitual and an integral part of her way of being, and the basis of an equilibrium reached in the dependent relationship with her mother and her twin sister. Behaviors of passivity, lack of interest, creativity and pro-activeness, are products of the extended time in missing use of verbal language as a necessary means to develop the formation of concepts, thoughts, complex thoughts, and metacognition. Despite F's functional evaluation, she has a normal intelligence level but her neuropsychological profile indicates poor cognitive functioning.

\section{Therapy}

Main objectives of individual therapy

\section{To change dysfunctional thoughts of:}

a) "Catastrophizing" and "Overgeneralization" compared to the consequences of speaking and the judgment of others: to speak does not necessarily provoke "negative judgments" by others. At this point it is necessary to reflect on different hypotheses of other one's judgments and on the fact that talking can bring about different consequences that can often be more "useful" than not talking at all. Additionally the consideration of the fact that it is "normal" that we might not be liked by others, but that this does not and should not damage our personal value and capacities is considered. Moreover the reflection on shame as being a natural emotion, that can appear in particular moments, is considered. (emotion acceptance process).

b) "Feelings of worthlessness" and sense of "incapacity" to speak: the promotion of autonomy and self-esteem. Not always do others laugh at what we say and if it happens that someone doesn't share the same opinion this doesn't mean that the content of speaking doesn't have any value, independent from ones self-esteem 
and a negative or positive evaluation of contingent situations (for example interrogation, speaking in front of strangers, etc.)

\section{To understand and label emotions:}

During the event simulation (to play and draw), F was asked at various times to indicate the emotion the character feels in that particular moment (by indicating the faces for each emotion or writing) with the scope to reflect carefully on the connection between events-emotions and their alternative consequences.

Main objectives of intervention in the family environment - Psycho-educational meetings with the parents of $\mathrm{F}$ and $\mathrm{L}$ on selective mutism disorder: $\mathrm{F}$ does not speak because she refuses to or throws tantrums as she feels a "discomfort" that makes her unable to speak. These meetings are mainly focused on changing the parents' interpretation and thoughts on F's mutacic behaviors.

- Indications on the parents' behavior at home:

1. To adopt a neutral attitude towards the non-speaking, to neither underline it frequently as a problem nor show a punitive approach;

2. No replacement of $\mathrm{F}$ in her daily activities and relationships. Whenever any person asks her a question it is important to leave space for the girl and never insist that she answers verbally, nor reply on her behalf. To involve her in the conversation whilst accepting other ways of communication (gestures, drawings, written text);

3. Home working and autonomy promotion: to let $\mathrm{F}$ gradually initiate small daily activities: for example pay at the newsstand, make a phone call, ask for information, etc.;

4. To increase social interactions with F's peers, if possible, separately from her sister and to create various individual spaces and locations;

5. To avoid comparisons between the two girls. To dedicate a single and separate location for and with $\mathrm{F}$.

Main objectives of intervention in the school environment It is very important to have a common approach both at home as at school to enforce the effects of intervention:

Teachers behavior in the classroom: a) neutral attitude towards the non-speaking enforcing the non-verbal communication with them and between F's peers; b) use of various disciplines (drawing, writing, open questions, multiple choice); c) promote and create activities in small groups with at least one peer with whom the girl talks to or gets along with.

\section{Critical analysis}

Selective mutism in the developmental age is a complex problem that depends on the interaction of multiple individual and environmental issues that are interweaved in various ways in the life of the girl. Therefore there is a strong necessity to explore all life situations, to attempt to involve the school, parents and teachers and to reconcile between therapeutic objectives and demands of the various life context of the child. The main scope of intervention in the various social areas of $F$ has collided against specific difficulties in the family-(e.g. the experiences of suffering of the mother) and school environment. It is often difficult to help parents to implement social relationships with the class or with other children. In F's case the twin condition, the diagnosis and the belated intervention, have been important factors in the maintenance of the disorder. The cognitive intervention has a strong connection with the evaluation of thoughts and the emotions underlying the mutacic disorder. Neuropsychological and emotional evaluation through structured tests that demand verbal methods and sufficient collaboration is not easy in a condition where there is no verbal communication (Pizzuto \& Capobianco, 2008). It is necessary to use various answering procedures (e.g. written, non-verbal, drawings) whilst keeping the maximum of validity during the administration of the tests. The evaluation of beliefs, cognitive biases and the behaviors of the child are fundamental to be able to structure the treatment program and it is necessary to "create" additional functional strategies and procedures to explore these aspects in each individual child.

\section{Consent}

Written informed consent for publication of their clinical details was obtained from the parent of the patient.

\section{Competing interests}

No competing interests were disclosed.

\section{Grant information}

The author(s) declared that no grants were involved in supporting this work.

\section{Acknowledgments}

The authors acknowledge the work of Dr. Liesbeth Elsink for the translation of this case report into English language. 
Capobianco M, Cerniglia L: Early language development in preterm children without neurological damage: a longitudinal study [version 1; referees: 2 approved]. F1000Res. 2017; 6: 2169.

PubMed Abstract | Publisher Full Text | Free Full Text

Capobianco M, Cerniglia L: Cognitive,emotional and behavioral iussues in

selective mutism: a narrative review on elements of a multimodal intervention.

Interacti Stud. (in press, next iussue). 2018

Reference Source

Capobianco M, Pizzuto EA, Devescovi A: Gesture-speech combinations and early verbal abilities. Interact Stud. 2017; 18(1): 55-76.

Publisher Full Text
Capobianco M, Riccio G, Devescovi A: Early communicative and language development in preterm infants without neurological damage. J Appl Res Intellect Disabil. 2010; 23(5): 513 .

Capozzi F, Manti F, Di Trani M, et al.: Children's and parent's psychological profiles in selective mutism and generalized anxiety disorder: a clinical study.

Eur Child Adolesc Psychiatry. 2017; 1-9.

PubMed Abstract | Publisher Full Text

Pizzuto EA, Capobianco M: Is pointing “just" pointing? Unraveling the complexity of indexes in spoken and signed discourse. Gesture. 2008; 8(1): 82-103.

Publisher Full Text 


\section{Open Peer Review}

\section{Current Peer Review Status:}

\section{Version 1}

Reviewer Report 12 March 2018

https://doi.org/10.5256/f1000research.15232.r31340

(C) 2018 Menghini D. This is an open access peer review report distributed under the terms of the Creative Commons Attribution License, which permits unrestricted use, distribution, and reproduction in any medium, provided the original work is properly cited.

\section{Deny Menghini}

Neuroscience Department, Children's Hospital Bambino Gesù, Rome, Italy

\section{Abstract:}

Please avoid References in the abstract.

\section{Introduction:}

Please avoid self-quotations in the Introduction. For example, cite other studies on etiological factors as Krysanski VL A brief review of selective mutism literature. J Psychol. 2003 Jan; 137(1):29-40. ${ }^{1}$

Diagnostic criteria for "selective mutism" definition are needed: include Diagnostic and Statistical Manual of Mental Disorders, DSM-5; APA, 2013, p. 195.

Cite other studies on single-cases: e.g. see Joseph PR. Selective mutism: the child who doesn't speak at school. Pediatrics 1999; 104:308-309 2

Please check the year in Capobianco \& Cernaglia (2017). In the Reference list is dated 2018.

Add references for the comorbidity of internalizing symptoms and selective mutism: see Diliberto RA, Kearney CA. Anxiety and oppositional behavior profiles among youth with selective mutism. J Commun Disord. 2016 Jan-Feb;59:16-23. ${ }^{3}$

Please, include other studies on the relationship between twins and mutism: e.g. Albrigtsen V, Eskeland B, Mæhle M. Ties of silence--Family lived experience of selective mutism in identical twins. Clin Child Psychol Psychiatry. 2016 Apr;21(2):308-234; Gensthaler A, Maichrowitz V, Kaess M, Ligges M, Freitag CM, Schwenck C. Selective Mutism: The Fraternal Twin of Childhood Social Phobia. Psychopathology. 2016;49(2):95-107. ${ }^{5}$

Last paragraph of the introduction: Please include references on the beneficial effect of CBT: see Walkup JT, Albano AM, Piacentini J, et al. Cognitive behavioral therapy, sertraline, or a 
combination in childhood anxiety. N Engl J Med 2008; 359:2753-2766. ${ }^{6}$

Details on the cognitive behavioral multimodal therapy are needed.

\section{Case report:}

Please describe in details neuropsychological measures (e.g. IQ) and instruments adopted for the assessment (anxiety scales as MASC, semi-structured interview as K-sads).

Avoid to mention "projective tests". Projective measures are not believed scientifically valid measures and they are not adopted as standard procedures for the assessment or diagnosis in literature and guidelines.

Avoid self-quotation in the "case report" session.

A brief description of familial history of psychopathological disorder (especially anxiety) shoul be included.

\section{Results:}

Please include a session of the main results of the present study obtained after the intervention and the measures used to verify the efficacy of the treatment.

\section{Discussion:}

In the Discussion, describe the significance of present findings in light of what was already known about the topic (previous literature), and explain new understanding about the problem.

Please, include limitations of the study.

For example, the lack of cognitive measures and psychopathological instruments (especially anxiety) for the assessment and the post-treatment evaluation.

\section{References}

1. Krysanski VL: A brief review of selective mutism literature.J Psychol. 2003; 137 (1): 29-40 PubMed Abstract | Publisher Full Text

2. Joseph PR: Selective mutism--the child who doesn't speak at school.Pediatrics. 1999; 104 (2 Pt 1): 308-9 PubMed Abstract

3. Diliberto RA, Kearney CA: Anxiety and oppositional behavior profiles among youth with selective mutism.J Commun Disord. 59: 16-23 PubMed Abstract | Publisher Full Text

4. Albrigtsen V, Eskeland B, Mæhle M: Ties of silence--Family lived experience of selective mutism in identical twins.Clin Child Psychol Psychiatry. 2016; 21 (2): 308-23 PubMed Abstract | Publisher Full Text

5. Gensthaler A, Maichrowitz V, Kaess M, Ligges M, et al.: Selective Mutism: The Fraternal Twin of Childhood Social Phobia.Psychopathology. 2016; 49 (2): 95-107 PubMed Abstract | Publisher Full Text

6. Walkup JT, Albano AM, Piacentini J, Birmaher B, et al.: Cognitive behavioral therapy, sertraline, or a combination in childhood anxiety.N EnglJ Med. 2008; 359 (26): 2753-66 PubMed Abstract | 
Is the background of the case's history and progression described in sufficient detail? No

Are enough details provided of any physical examination and diagnostic tests, treatment given and outcomes?

No

Is sufficient discussion included of the importance of the findings and their relevance to future understanding of disease processes, diagnosis or treatment?

No

Is the case presented with sufficient detail to be useful for other practitioners? Yes

Competing Interests: No competing interests were disclosed.

Reviewer Expertise: Neurodevelopmental Disorders

I confirm that I have read this submission and believe that I have an appropriate level of expertise to confirm that it is of an acceptable scientific standard.

Reviewer Report 06 March 2018

https://doi.org/10.5256/f1000research.15232.r31484

(C) 2018 Bozzali M. This is an open access peer review report distributed under the terms of the Creative Commons Attribution License, which permits unrestricted use, distribution, and reproduction in any medium, provided the original work is properly cited.

Marco Bozzali

Clinical Imaging Science Center, Brighton and Sussex Medical School, Brighton, UK

The manuscript by Capobianco \& Cerniglia investigates the selective mutism phenomenon in twins.

The study is interesting and well written and it improves the knowledge about mutacic difficulties in children. I accept the paper with minor revision:

1. The Authors in the Conclusion section of the manuscript should better clarify the modalities of intervention on the two twins interaction.

2. A table with neuropsychological scores should be added to the manuscript to better clarify the patient's cognitive profile.

Is the background of the case's history and progression described in sufficient detail? Yes 
Are enough details provided of any physical examination and diagnostic tests, treatment given and outcomes?

Yes

Is sufficient discussion included of the importance of the findings and their relevance to future understanding of disease processes, diagnosis or treatment?

Yes

Is the case presented with sufficient detail to be useful for other practitioners?

Yes

Competing Interests: No competing interests were disclosed.

I confirm that I have read this submission and believe that I have an appropriate level of expertise to confirm that it is of an acceptable scientific standard.

Reviewer Report 26 February 2018

https://doi.org/10.5256/f1000research.15232.r31146

(C) 2018 Fasolo $\mathbf{M}$. This is an open access peer review report distributed under the terms of the Creative Commons Attribution License, which permits unrestricted use, distribution, and reproduction in any medium, provided the original work is properly cited.

\section{Mirco Fasolo}

Department of Neuroscience, Imaging and Clinical Sciences, University of Chieti-Pescara, Chieti, Italy

26/02: This peer review report was mistakenly published with an Approved with Reservations status. It has now been corrected to an Approved.

I have reviewed the Case Report "Evaluation strategies and cognitive intervention: the case of a monovular twin child affected by selective mutism".

I think that the paper is well written and offers a relevant clinical and research contribution to studies on selective mutism, a little know disorder that consists in an "inability to talk in unfamiliar contexts".

The case of a child monovular twin is very interesting because it allows to evidence the link between biological and environmental factors.

I accept the work but I think that:

It is necessary to insert more details on the clinical case.

The child is a twin and interaction with her sister is a though factor for maintaining the mutacic behaviour, so, the relationships between the two sisters must be better presented. 
The cognitive-behavioural is the best approach for children with mutism. The authors can mention also others approaches for comparison (e.g. psychodynamic approach).

Early diagnosis and surgery of selective mutism must be briefly presented.

Some misprints are present in the text.

Is the background of the case's history and progression described in sufficient detail? Yes

Are enough details provided of any physical examination and diagnostic tests, treatment given and outcomes?

Yes

Is sufficient discussion included of the importance of the findings and their relevance to future understanding of disease processes, diagnosis or treatment?

Partly

Is the case presented with sufficient detail to be useful for other practitioners? Yes

Competing Interests: No competing interests were disclosed.

I confirm that I have read this submission and believe that I have an appropriate level of expertise to confirm that it is of an acceptable scientific standard.

The benefits of publishing with F1000Research:

- Your article is published within days, with no editorial bias

- You can publish traditional articles, null/negative results, case reports, data notes and more

- The peer review process is transparent and collaborative

- Your article is indexed in PubMed after passing peer review

- Dedicated customer support at every stage

For pre-submission enquiries, contact research@f1000.com 